\title{
Indicadores de sostenibilidad para un cultivo de pimiento en el valle de Azapa, Arica, Chile
}

\author{
Indicators of sustainability for a pepper crop in the Azapa Valley, Arica, Chile
}

\author{
Pilar Mazuela ${ }^{1}$
}

\begin{abstract}
RESUMEN
Los valles costeros de la región de Arica y Parinacota presentan condiciones climáticas excepcionales para el cultivo de hortalizas durante todo el año, siendo el principal proveedor de hortalizas para el país durante el invierno. La producción media regional de pimiento supera significativamente la media nacional, con un alto valor comercial por la condición de "primor" que hace de su cultivo una actividad muy competitiva a nivel nacional. La demanda de los consumidores por productos de calidad ha generado cambios para que los procesos de producción sean sustentables. El objetivo de este trabajo fue determinar los indicadores económicos, sociales y medioambientales para el pimiento bajo las condiciones de cultivo en el valle de Azapa. El manejo del cultivo puede ser mejorado para dar sustentabilidad a esta actividad al conocer estos indicadores.
\end{abstract}

Palabras clave: sustentabilidad, contraestación, medioambiente, rendimiento, producción.

\begin{abstract}
The coastal valleys of the Region Arica y Parinacota (Chile) have exceptional climatic conditions for vegetable crops during the entire year; they are the main provider of vegetables in the country in winter. The mean regional production of pepper is greater than the national mean and have a high commercial value due to the off season condition that makes it's a very competitive activity in this country. Demand of consumers for quality products is very important to change to sustainable crop management. The aim of this work was to determine economic, social and environmental indicators for pepper crop in Azapa's Valley. The management of pepper crop can be improved to give sustainability to this activity when knowing these indicators.
\end{abstract}

Key words: sustainability, off-season, environment, yield, production.

\section{Introducción}

Los valles costeros de la región de Arica y Parinacota presentan condiciones climáticas excepcionales para el cultivo de hortalizas durante todo el año, siendo el principal proveedor de hortalizas para el país durante el invierno. La producción media regional de pimiento supera significativamente la media nacional, con un alto valor comercial por la condición de "primor" que hace de este cultivo una actividad muy competitiva a nivel nacional. Para mejorar el proceso de producción, se debe conocer los indicadores económicos, sociales y medioambientales, pues no se entiende un cultivo y su producción desligados de las consideraciones sociales y medioambientales. Actualmente, se usan algunos términos descriptivos o indicativos de una normativa o "etiqueta" que regula los procesos de producción para que el horticultor pueda ser más competitivo como, por ejemplo, cultivo ecológico, agricultura sostenible, sustentable, agricultura no contaminante y amigable con el medio ambiente, producción controlada, producción integrada, etc. Todos ellos tienen en común un intento de racionalizar la producción con mayor o menor grado de exigencia y limitaciones en el sistema productivo.

El término desarrollo sustentable se formalizó por primera vez con el Informe Brundtland, de 1987, como resultado de la Comisión Mundial de Medio Ambiente y Desarrollo de las Naciones Unidas. En 1992, durante la Cumbre del Planeta Tierra, se presentó el Programa 21, donde se recogieron las bases de un desarrollo sustentable

1 Departamento de Producción Agrícola, Universidad de Tarapacá, Arica, Chile, pmazuela@uta.cl

Fecha de Recepción: 2 Junio, 2017

Fecha de Aceptación: 11 Agosto, 2017

DOI: 
para el Siglo XXI (Fernández-Zamudio y Caballero, 2006). Algunos aspectos del desarrollo sustentable consideran que los recursos renovables no pueden utilizarse a un ritmo superior al de su generación y los contaminantes no pueden producirse a un ritmo superior al que puedan ser reciclado, neutralizado o absorbido por el medio ambiente (Bartlett, 1999). La sostenibilidad o sustentabilidad agrícola, es un término para expresar la necesidad de generar condiciones que permitan que esta actividad pueda permanecer durante el tiempo.

La agricultura intensiva, como la producción de hortalizas en contraestación, es sometida a análisis críticos por sus efectos en el medioambiente. La demanda de los consumidores por productos de calidad ha generado cambios en el manejo de cultivos para optimizar la producción y calidad de las hortalizas. Estos no solamente demandan productos de calidad sino, además, valoran que los procesos de producción sean sustentables. El desarrollo sostenible es una de las actividades de mayor importancia para las economías y la construcción de esta información debe ser sistemática, fiable y con criterios homogéneos que permitan la comparación entre regiones y países. Al promover el desarrollo sostenible hay que considerar la geografía particular en un ambiente semiárido con realidades económicas, sociales y ecológicas distintas al resto del país.

La demanda de los consumidores por productos de calidad ha generado cambios en el manejo de cultivos para optimizar la producción y calidad de las hortalizas. Estos no solamente demandan productos de calidad sino, además, valoran que los procesos de producción sean sustentables. La sostenibilidad o sustentabilidad agrícola, es un término para expresar la necesidad de generar condiciones que permitan que esta actividad pueda permanecer durante el tiempo. Espina (1971) advierte acerca de los factores de manejo que más inciden en la productividad en el valle de Azapa, siendo los más importantes el control fitosanitario del suelo, el manejo del agua de riego y la aplicación de fertilizantes, situación que persiste hasta hoy (González-Vallejos et al., 2013). Hasta 2004, la única hortaliza que podía salir fuera de la provincia de Arica hacia el sur del país, era el tomate, previo tratamiento cuarentenario para el control de la mosca de la fruta (Ceratitis capitata). A contar de esa fecha, se pudo diversificar la producción de hortalizas como se observa en la Tabla 1. Después del tomate, el pimiento es el cultivo más importante, desde el punto de vista económico, por sus altos requerimientos de insumos y uso intensivo en mano de obra. El objetivo de este trabajo fue determinar los indicadores económicos, sociales y medioambientales para el pimiento bajo las condiciones de cultivo en el valle de Azapa.

\section{Material y Método}

\section{Localización y descripción general}

Para la construcción de los indicadores de sustentabilidad se hizo el seguimiento al proceso productivo de siete invernaderos con cultivo de pimiento entre los $\mathrm{Km} 3$ a 20 del valle de Azapa, Arica, Chile. Los sistemas productivos fueron representativos de los distintos procesos

Tabla 1. Superficie cultivada de hortalizas seleccionadas, según Censo Agropecuario 1997 y 2007 , y Encuesta Hortícola año 2009 al 2016, con medias productivas $\left(\mathrm{kg} \mathrm{m}^{-2}\right)$ por región y país.

\begin{tabular}{|c|c|c|c|c|c|c|c|c|c|c|c|c|}
\hline & \multicolumn{10}{|c|}{ Superficie cultivada (ha) por año, según Censo y Encuesta Hortícola } & \multirow{2}{*}{\multicolumn{2}{|c|}{ Producción 4}} \\
\hline & \multicolumn{2}{|c|}{ Censo } & \multicolumn{8}{|c|}{ Encuesta hortícola ${ }^{3}$} & & \\
\hline & $1997^{1}$ & $2007^{2}$ & 2009 & 2010 & 2011 & 2012 & 2013 & 2014 & 2015 & 2016 & Región & País \\
\hline Calabacín & 34,1 & 105,6 & 118 & 110 & 104 & 120 & 118 & 133 & 149 & 207 & - & - \\
\hline Judías* & 308,7 & 174,7 & 170 & 144 & 84 & 116 & 96 & 112 & 124 & 110 & 9.810 & 8.370 \\
\hline Melón*** & & 12,8 & 9 & - & 8 & 8 & 10 & 19 & 4 & 4 & - & 26.890 \\
\hline Pepino & 20,3 & 37,3 & - & - & 18 & 25 & 35 & 57 & 61 & 68 & - & - \\
\hline Pimiento* & 85,8 & 138,4 & 144 & 138 & 116 & 136 & 148 & 143 & 160 & 172 & 46.500 & 36.960 \\
\hline Sandía** & & 0 & & & & 2 & 5 & 1 & 3 & 2 & - & 7.980 \\
\hline Tomate* & 448,5 & 840,1 & 653 & 715 & 685 & 821 & 594 & 688 & 750 & 672 & 112.860 & 71.100 \\
\hline
\end{tabular}

Fuente: ${ }^{1}$ INE, 1999; ${ }^{2}$ INE, 2008; ${ }^{3}$ INE, 2017. Encuesta hortícola en base al VII Nacional Agropecuario y Forestal, $2007 ;{ }^{4}$ INE, 2010 :

Producción *kg há1; **unidades há ${ }^{1}$.

- Sin estimación. 
de producción de pimiento producido en contraestación y tenían en común la cubierta plástica para evitar que el cultivo se vea afectado por las bajas temperaturas durante el invierno. Los invernaderos fueron muy heterogéneos entre sí respecto al tamaño, altura, densidad de plantación y variedad de pimiento utilizada.

\section{Indicadores económicos}

Se consideraron tres parámetros económicos: productividad media, rentabilidad y calendario comercial. La productividad media se calculó en base al promedio de kilogramos comerciales obtenidos por metro cuadrado $\left(\mathrm{Kg} \mathrm{m}^{-2}\right)$. $\mathrm{La}$ rentabilidad se calculó según la relación margen neto por costos totales y se expresó en base a un índice entre 0 y 1 . El calendario comercial se calculó en base a la media de semanas de inicio a fin de cosecha y se expresó en semanas.

\section{Indicadores sociales}

Los indicadores sociales considerados fueron: generación de empleo y estacionalidad del empleo. La generación de empleo, se calculó en base a la media de jornales durante la duración del cultivo. Cada jornal equivale al trabajo de un hombre durante ocho horas. La estacionalidad del empleo se refiere a la temporalidad del empleo en relación al año calendario y se expresa en un indicador que va de 0 a 1 .

\section{Indicadores medioambientales}

Se consideraron dos indicadores medioambientales: la eficiencia del agua en la producción y los vertidos totales al año. Para el cálculo de la eficiencia del agua en la producción se consideró la media de kilogramos de pimientos comerciales producidos por $\mathrm{m}^{3}$ de agua aportado, expresado en $\mathrm{Kg} \mathrm{m}^{-3}$. Para el cálculo de los vertidos totales, se cuantificó la media de desechos orgánicos por superficie, al año, expresado en toneladas por hectárea $\left(\mathrm{t} \mathrm{ha}^{-1}\right)$.

\section{Discusión de resultados}

Los resultados de la disolución nutritiva resultante se indican en la Tabla 2. Los resultados económicos indican que los valores de producción media duplican a los indicados por el INE (2010), lo que podría explicarse por una aumento en un $20 \%$ del calendario comercial, respecto al indicado por la misma fuente. El indicador de rentabilidad (margen neto/costos totales) es mayor al indicado por Fernández-Zamudio y Caballero (2006), lo que puede explicarse por el alto valor comercial que tiene el pimiento durante el invierno.

Los indicadores sociales indican que la generación de empleo es significativamente superior a la indicada por Fernández-Zamudio y Caballero (2006), esto puede explicarse por el mayor período de cultivo que tiene el pimiento en el valle de Azapa y por la alta tecnificación que existe en Europa por el costo de la mano de la mano de obra. Respecto a los indicadores medioambientales, los resultados indican que la productividad del agua es superior a la indicada por Fernández-Zamudio y Caballero (2006), aunque los vertidos totales son mayores a los indicados por Sepúlveda et al, 2010, los que son proporcionales a la producción media y al calendario comercial o semanas de cosecha.

Tabla 2. Indicadores de sustentabilidad económica (E), social (S) y medioambiental (MA), según referencia y resultados de la media del cultivo de pimiento en el valle de Azapa.

\begin{tabular}{clccc}
\hline Tipo & \multicolumn{1}{c}{ Indicador } & Unidad & Referencia & Resultado \\
\hline E & Producción media & $\mathrm{Kg} \mathrm{m}^{-2}$ & $4,65^{1}$ & 11 \\
E & Margen neto/costos totales & $0-1$ & $0,36^{2}$ & 0,44 \\
E & Calendario comercial & Semanas & 241 & 30 \\
S & Generacion de empleo & Jornales & $332^{2}$ & 847 \\
S & Estacionalidad del empleo & $0-1$ & $0,54^{2}$ & 0,54 \\
MA & Eficiencia del agua en la producción & $\mathrm{Kg} \mathrm{m}^{-3}$ & $11,87^{2}$ & 13,6 \\
MA & Vertidos totales & $\mathrm{T} \mathrm{ha}^{-1}$ & 273 & 29,3 \\
\hline
\end{tabular}

1INE, 2010. ${ }^{2}$ Fernández-Zamudio y Caballero, 2006. ${ }^{3}$ Sepúlveda et al., 2010. 


\section{Conclusión}

Los indicadores de sustentabilidad indican que el cultivo de pimiento tiene mejores resultados que los indicadores de referencia, excepto para los vertidos totales orgánicos, los que pueden ser reutilizados como compost en el mismo cultivo. Los resultados sugieren que el cultivo de pimiento es competitivo y sustentable bajo las condiciones productivas del valle de Azapa.

\section{Agradecimientos}

Este trabajo ha sido financiado por el proyecto UTA Mayor 9720-14.

\section{Literatura Citada}

Bartlett, A.A.

1999. Reflexiones sobre sostenibilidad, crecimiento de la población y medio ambiente. Focus, 9 (1): 49-68.

Espina, L.

1971. Estudio agroeconómico del valle de Azapa. Junta de Adelanto de Arica, Universidad de Chile. Santiago, Chile, 155 p.

Fernández-Zamudio, M.; Caballero, P.

2006. La necesidad de cuantificar la sostenibilidad de los invernaderos. Vida Rural, 239: 49-54.

González-Vallejos, F.; Riquelme-Garcés, A.; Contreras-Luque,

P.; Mazuela, P.

2013. Antecedentes generales para la sustentabilidad de la producción hortícola en el valle de Azapa, Arica, Chile. Idesia, (31)4: 119-123.

Instituto Nacional de Estadísticas

2017. Estadísticas Agrícolas, Informe de Cultivo de hortalizas. Disponible en: http://www.ine.cl/estadis-
ticas/economicas/estad\%C3\%ADsticas-agropecuarias?categoria $=$ Estad\%C3\%ADsticas\%20Agr\%C3\%ADcolas. Consultado: 23/Ago/2017.

Instituto Nacional de Estadísticas

2010. Información Hortícola. Publicación Especial 20082009. INE Ediciones. Santiago, Chile, 128 p.

Instituto Nacional de Estadísticas

1999. VI Censo Nacional Agropecuario, Región Tarapacá. Edición Rossana Espinosa Peralta. Iquique, Chile, $473 \mathrm{p}$.

Instituto Nacional de Estadísticas 2008. VII Censo Agropecuario y Forestal 2006-2007. Resultados preliminares. INE Ediciones. Santiago, Chile, $444 \mathrm{p}$.

Sepúlveda, F.; Tapia, F.; Ardiles, S.

2010. Manejo de residuos en el valle de Azapa. Tierra Adentro, 90: 14-16. 